\title{
Haemodynamic changes during propofol induction in dogs: new findings and approach of monitoring
}

\author{
Andrea Cattai ${ }^{1}$, Roberto Rabozzi ${ }^{2 *}$, Heidi Ferasin ${ }^{3}$, Maurizio Isola ${ }^{1}$ and Paolo Franci ${ }^{1}$
}

\begin{abstract}
Background: Propofol is one of the most widely used injectable anaesthetic agents in veterinary practice. Cardiovascular effects related to propofol use in dogs remain less well defined. The main objective of this study was to evaluate the haemodynamic changes during induction of general anaesthesia with propofol in healthy dogs, by a beat-to-beat continuous monitoring. All dogs were premedicated with intramuscular acepromazine $(0.015 \mathrm{mg} / \mathrm{kg})$ and methadone $(0.15 \mathrm{mg} / \mathrm{kg})$. Transthoracic echocardiography was used to measure the velocity time integral (VTI) of the left ventricular outflow tract. A syringe driver, programmed to deliver propofol $5 \mathrm{mg} / \mathrm{kg}$ over $30 \mathrm{~s}$ followed by a continuous infusion of $25 \mathrm{mg} / \mathrm{kg} / \mathrm{h}$, was used to induce and maintain anaesthesia. From the initiation of propofol administration, heart rate (HR) and mean invasive arterial blood pressure (MAP) were recorded every $5 \mathrm{~s}$ for $300 \mathrm{~s}$, while aortic blood flow was continuously recorded and stored for $300 \mathrm{~S}$. maximum cardiovascular depression was defined the lowest MAP (MAP_Tpeak) recorded during the monitored interval. VTI and VTI*HR were calculated at 0, 30, 90, 120, 150 and 300 s post administration of propofol, and at MAP_Tpeak. Haemodynamic effects of propofol in relation to plasma and biophase concentrations were also evaluated by pharmacokinetics simulation.

Results: The median (range) HR was significantly higher $(p=0.006)$ at the moment of maximum hemodynamic depression (Tpeak) [105(70-148) bpm] compared with pre-induction values (T0) [65(50-120) bpm]. The median (range) MAP was significantly lower $(p<0.001)$ at Tpeak [61(51-69) $\mathrm{mmHg}$ ] compared with T0 [88(72-97) mmHg]. The median (range) VTI and VTI*HR were similar at the two time points [11.9(8.1-17.3) vs 13,3(9,4-16,5) cm, and 1172(806-1554) vs 1002(630-1159) cm*bpm, respectively].

Conclusions: Induction of anaesthesia with propofol causes a drop of arterial pressure in healthy dogs, however cardiac output is well maintained by compensatory chronotropic response. The magnitude of MAP_Tpeak may be strictly related with propofol plasma concentration.
\end{abstract}

Keywords: Propofol, Haemodynamic effects, Baroreflex, Anaesthesia, Transthoracic echocardiography, Dog

\section{Background}

Induction of anaesthesia in dogs can be accomplished by using propofol (2,6-di-isopropylphenol), one of the most widely used injectable anaesthetic agents in veterinary practice. Cardiovascular effects related to propofol use have been subjected to intense research, often using the $\operatorname{dog}$ as a research model and with conflicting results. Blood pressure (BP) decrease is a common finding when

\footnotetext{
* Correspondence: rob.rabozzi@gmail.com

${ }^{2}$ CVRS - Policlinico Veterinario Roma Sud, Rome, Italy

Full list of author information is available at the end of the article
}

propofol is used to induce anaesthesia in dogs [1-7]. Several mechanisms have been suggested as possible contributory causes of cardiovascular effects of propofol at clinically relevant concentrations: decrease in left ventricular preload produced by direct venous vasodilatation $[8,9]$; reduction in systemic vascular resistance by arterial relaxation, most likely due to inhibition of sympathetic nervous system activity $[2,10]$ and negative inotropic effect [11-13].

The heart rate response to propofol administration in dogs remains less well defined. After different doses of propofol administered intravenous (IV) in dogs, either a

(c) The Author(s). 2018 Open Access This article is distributed under the terms of the Creative Commons Attribution 4.0 International License (http://creativecommons.org/licenses/by/4.0/), which permits unrestricted use, distribution, and 
significant increase of heart rate (HR) [1,2] or no significant chronotropic effects [3-5, 7] have been reported. Propofol has also shown conflicting results on attenuation of baroreflex function in other species, either demonstrating no effect or attenuation related to propofol blood concentration [14-18].

One of the difficulties in monitoring hemodynamic changes during induction of general anaesthesia is the ability to record the rapidly occurring cardiovascular variations in a subject which moves from being fully conscious to being anaesthetised. Beat-to-beat monitoring of the cardiac stroke volume is crucial to accomplish this task. In this respect, transthoracic echocardiography has some advantages over other methods of cardiovascular monitoring, being a non-invasive technique that allows quantitative assessment of left ventricular function. Cardiac ultrasound machines are also widely available in the veterinary field and, therefore, it does not normally incur further financial expenses. Its use to monitor haemodynamic changes during anaesthesia has been reported [19, 20]. Doppler echocardiography can be used as a method to monitor velocity time integral (VTI) variations of the aortic blood flow during and after administration of drugs in dogs [21], which is commonly used to evaluate stroke volume (SV) variation on the same subject [21-26]. Pulsed Doppler echocardiographic assessment of cardiac output (CO) is a validated non-invasive method in humans $[27,28]$.

The aim of the present study was to investigate the haemodynamic changes produced by propofol, administered intravenously over $30 \mathrm{~s}$ in healthy dogs, through the use of continuous monitoring of electrocardiograph (ECG), invasive BP and trans-aortic flow over $300 \mathrm{~s}$. Haemodynamic effects of propofol in relation to plasma and biophase concentrations were also evaluated by pharmacokinetics simulation.

\section{Methods}

The study was approved by the Ethic Committee of the University of Padua (Prot. N. 89,556).

\section{Animals}

Dogs admitted to the Ospedale Veterinario Roma Sud for various scheduled procedures were eligible for enrolment in the study. All animals underwent a physical examination and blood test analysis. Dogs were excluded from the study if owner consent was not granted, if the subject was assigned to American Society of Anesthesiology (ASA) physical status classification more than I, if they were $<1$ year of age, or had a temperament that precluded use of a standard anaesthetic technique.

\section{Study protocol}

Dogs were premedicated with acepromazine $0.015 \mathrm{mg} / \mathrm{kg}$ (Fatro S.p.A., Ozzano dell'Emilia, Italy) and methadone
$0.15 \mathrm{mg} / \mathrm{kg}$ (Dechra, Bladel, Netherlands) mixed in the same syringe and administered intramuscularly. After $40 \mathrm{~min}$, two over-the-needle catheters were aseptically inserted, one into a cephalic vein and another one in a dorsal pedal artery. Cardiovascular and respiratory variables were monitored by a multiparameter monitor (Datex Ohmeda AS/3, GE Healthcare). Dogs were positioned in a right lateral recumbent position and continuous ECG monitoring and invasive BP monitoring was started. Hair was clipped over the xiphoid area. Transthoracic echocardiography was used to measure the VTI of the left ventricular outflow tract, with a phased array PA240 probe (Esaote MyLab $70 \mathrm{CV}$ ). Sweep speed during recordings was set to $240 \mathrm{~Hz}(180-300 \mathrm{~Hz})$. Optimised subcostal standard view of the left ventricular inflow and outflow tracts was used for data acquisition. Two-dimensional cine loops and Doppler tracings were recorded and stored on the internal hard drive of the echocardiograph and off-line analysed. The system was set to store raw DICOM data.

In order to induce anaesthesia a $50 \mathrm{ml}$ syringe loaded with propofol (Esteve, Milano, Italy) was mounted on a syringe driver (Graseby 3500, Smiths Medical, England), which was programmed to intravenously deliver $5 \mathrm{mg} /$ $\mathrm{kg}$ over $30 \mathrm{~s}$, followed by a continuous infusion of $25 \mathrm{mg} / \mathrm{kg} / \mathrm{h}$ to induce and maintain anaesthesia. At 2 min from initiation of the infusion the dog was assessed the first time to determine if endotracheal intubation was possible. When weakened palpebral reflex, rostromedial rotation of the eyeball, reduction in jaw tone and lack of tongue withdrawal were obtained, endotracheal intubation was facilitated and the dog was connected to a circle breathing system for $100 \%$ oxygen delivery. If a dog became apnoeic (no spontaneous ventilation for $30 \mathrm{~s}$ ) or hypercapnic, it was manually ventilated until it was able to spontaneously maintain normocapnia (35- $50 \mathrm{mmHg}$ ).

Trans-aortic flow was continuously recorded for $300 \mathrm{~s}$, after the beginning of the infusion. Heart rate and systolic, diastolic and mean arterial blood pressure (MAP) were also recorded every $5 \mathrm{~s}$ for $300 \mathrm{~s}$, using an electronic spread sheet throughout available via a commercial software (Monitor Software version 6.1, University of Hong Kong). Data were downloaded onto a laptop computer connected to the anaesthesia monitor by a serial port adaptor. Aortic velocity time integral was obtained from digital still images as a mean of 10 consecutive measurements, which were obtained during spontaneous breathing. Only high-quality images were used for data analysis. All measurements were made off-line by an investigator (RR). Maximum cardiovascular depression was defined the lowest MAP (MAP_Tpeak) recorded during the monitored interval (Tpeak). VTI and VTI*HR (minute distance) were calculated at $0,30,90,120,150$ and $300 \mathrm{~s}$ post administration of propofol, and at Tpeak. 
A pharmacokinetics (PK) simulation of the anaesthetic protocol used in this study was carried out, running on a personal computer the Computer Control Infusion Pump V.2.0E software, programmed with a validated PK model [29] and a specific $K_{\mathrm{e} 0}$ [30]. During the simulation this software provided data of the predicted propofol plasma concentration, and the related estimated effect-site concentration every $5 \mathrm{~s}$.

\section{Statistical analysis}

Continuous variables were checked for normal distribution by visual inspection of the bar graph, frequency of distribution and performing the Shapiro-Wilk normality test. Variables that were normally distributed were reported as the mean and standard deviation, whereas non-normally distributed variables were expressed as the median (range). Friedman Test was used to analyse differences within subjects and Dunn's post hoc test was applied. The significant level was set at 5\%. According to a priori power analysis (Power $=80 \%, \alpha=0.05$ ), based on previously reported data on HR and MAP variations in dogs treated with a similar anaesthesia protocol [7], $\geq 4$ subjects needed to detect significant effects. Statistical analysis was performed using MedCalc Software version 12.6.1.0 and Dell Statistica Software version 13.1.

\section{Results}

Eight mixed breed dogs ( 2 males and 6 females) were included in this study. Median age and median body weight were 54 months (18-120 months) and $17 \mathrm{~kg}(6-35 \mathrm{~kg})$, respectively. The median intubation time after the start of the propofol infusion was 140 (130-180) seconds. Neither apnoea, nor other anaesthetic-related adverse effects were observed.

The changes in haemodynamic variables, at different time points after the bolus of propofol, are shown in Table 1 and Figs 1, 2, 3 and 4. There was a significant increase in the HR at Tpeak $(p<0.01), 120$ and $150 \mathrm{~s}(p<0.05)$, compared to the baseline. There was a significant decrease in the MAP at Tpeak $(p<0.001), 90$ and $300 \mathrm{~s}(p<0.05)$, and in the VTI at 120, 150 and $300 \mathrm{~s}(p<0.05)$.

Based on the pharmacokinetics simulation, the estimated peak plasma concentration $\left(6.24 \mu \mathrm{gml}^{-1}\right)$ of propofol (Cmax) was reached after $30 \mathrm{~s}$ and at the time of equilibration between plasma and biophase (five and a half minutes) was $5.68 \mu \mathrm{gml}^{-1}$.

\section{Discussion}

In this study a bolus of $5 \mathrm{mg} / \mathrm{kg}$ of propofol, administered over $30 \mathrm{~s} \mathrm{IV}$, caused a rapid drop in arterial BP, however cardiac output was well maintained by a significant rise in HR.

The reduction in arterial $\mathrm{BP}$, following propofol administration, can be due to any mechanism acting on both cardiac output and systemic vascular resistance. $\mathrm{CO}$ is expressed as the product of SV and HR. SV depends on three primary factors (preload, afterload, and myocardial contractility), all of which are interrelated. The direct negative inotropic effect of propofol seems to be relatively small when it is used within clinical concentrations [13, 31]. Most likely, the decrease in BP arises primarily as a result of the vasodilatory effect of propofol. This could be due to both, a reduction of sympathetic tone and a direct effect on smooth muscle. Induction of anaesthesia with propofol in dogs has been demonstrated to result in a dose-dependent decrease of systemic vascular resistance [2].

Arterial baroreflex function is an important short-term neural control system for maintaining cardiovascular stability. Attenuation of this reflex by propofol, due to a central or peripheral effect on sympathetic nervous activity, has been reported in humans $[17,18]$. Sato et al. [18] reported that an estimated blood propofol concentration of $5 \mu \mathrm{g} \mathrm{ml}{ }^{-1}$ would result in baroreflex inhibition. Running the pharmacokinetics simulation of the protocol of administration used in our study, this concentration was already achieved and exceeded at the end of the $30 \mathrm{~s}$ bolus of propofol. Other studies, in humans and other species, have shown no or only slight effects on baroreflex sensitivity

Table 1 Haemodynamic variables in dogs $(n=8)$ receiving a bolus of $5 \mathrm{mg} / \mathrm{kg}$ of propofol, administered over $30 \mathrm{~s}$ IV, at different time points

\begin{tabular}{|c|c|c|c|c|c|c|c|}
\hline & Pre-induction & $30 \mathrm{~s}$ & $\begin{array}{l}\text { Tpeak } \\
55(50-60) \text { sec }\end{array}$ & $90 \mathrm{~s}$ & $120 \mathrm{~s}$ & $150 \mathrm{~s}$ & $300 s$ \\
\hline$\overline{\mathrm{HR}}$ & $65(50-120)$ & $76(50-130)$ & $105(70-148))^{* *}$ & $87(54-162)$ & $91(55-154)^{*}$ & $106(50-146)^{*}$ & $82(53-135)$ \\
\hline MAP & 88 (72-97) & $88(71-99)$ & $61(51-69)^{* * *}$ & $70(50-79)^{*}$ & $71(59-82)$ & 76 (49-90) & $68(61-88)^{*}$ \\
\hline $\mathrm{VTI}$ & $13.3(9.4-16.5)$ & $12.2(8-18)$ & $11.9(8.1-17.3)$ & $11.5(8.5-13.5)$ & $11.8(7.9-13.3)^{*}$ & $11.6(7.7-14.3)^{*}$ & $10.9(7.5-14.7)^{*}$ \\
\hline$V T I^{*} H R$ & 1002 (630-1159) & $899(537-1705)$ & 1172 (806-1554) & 952 (629-1377) & $1053(678-1262)$ & 1082 (593-1516) & $950(616-1254)$ \\
\hline
\end{tabular}

Tpeak, moment of maximum haemodynamic depression; HR, heart rate (beats minute-1); MAP, mean arterial pressure (mmHg); VTI, velocity time integral (centimetres) Data expressed as median (range)

Values significantly different from pre-induction

$* 0.01<p<0.05$

${ }^{* *} 0.001<p<0.01$

${ }^{* * *} p<0.001$ 


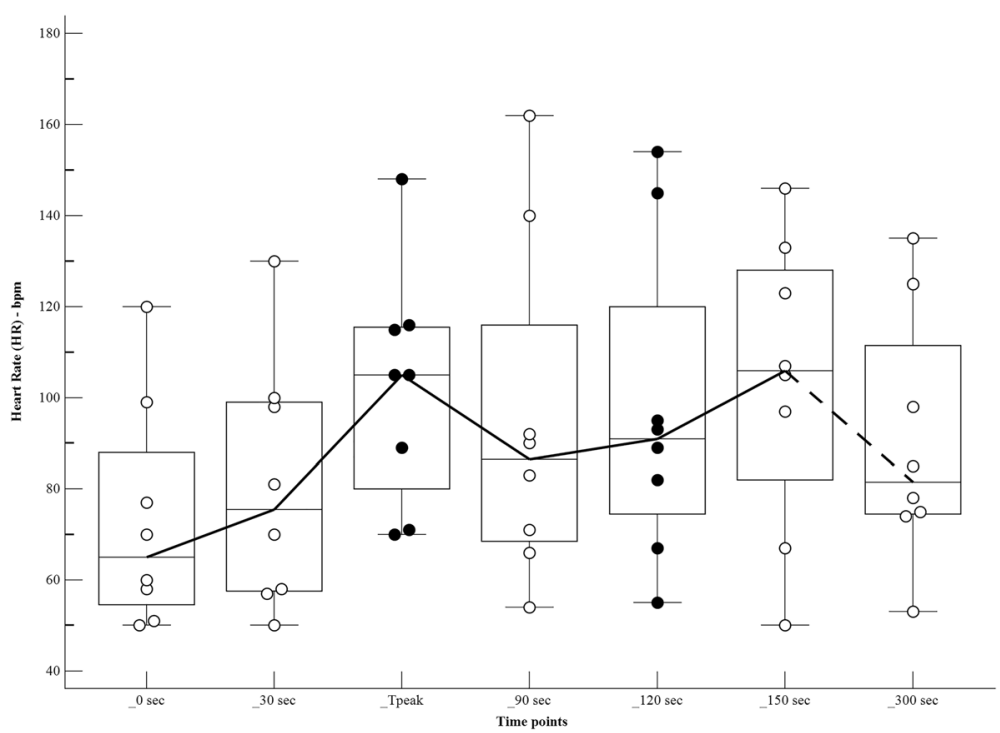

Fig. 1 Values of heart rate (beats minute ${ }^{-1}$ ) in dogs $(n=8)$ receiving a bolus of propofol at different time points. The central box represents the values from the lower to upper quartile. The middle line represents the median. Time points non-significantly different (empty circles) and significantly different (full circles) from the baseline

[14-16]. Our results in dogs seem to be in agreement with the latter. The continuous recording of arterial BP in this study allowed identification of the time of maximal hemodynamic depression as occurring after about one minute [55 (50-60) sec] from the start of propofol administration. Based on the pharmacokinetics simulation, the Cmax of propofol was reached close to MAP_Tpeak, while the peak of the estimated propofol biophase concentration occurred about four and a half minutes later. In humans, the maximal BP depression is reached about 2.5 min after the administration of a bolus of propofol to induce anaesthesia $[16,32]$. This delay is similar to the time to peak propofol effect-site concentration that is reported for adult patients [32, 33]. This remarkable difference suggests that the mechanism mainly involved in causing the decrease of BP may be different between the two species. Looking at the time to peak effect in humans, which is quite close to the peak of cardiovascular

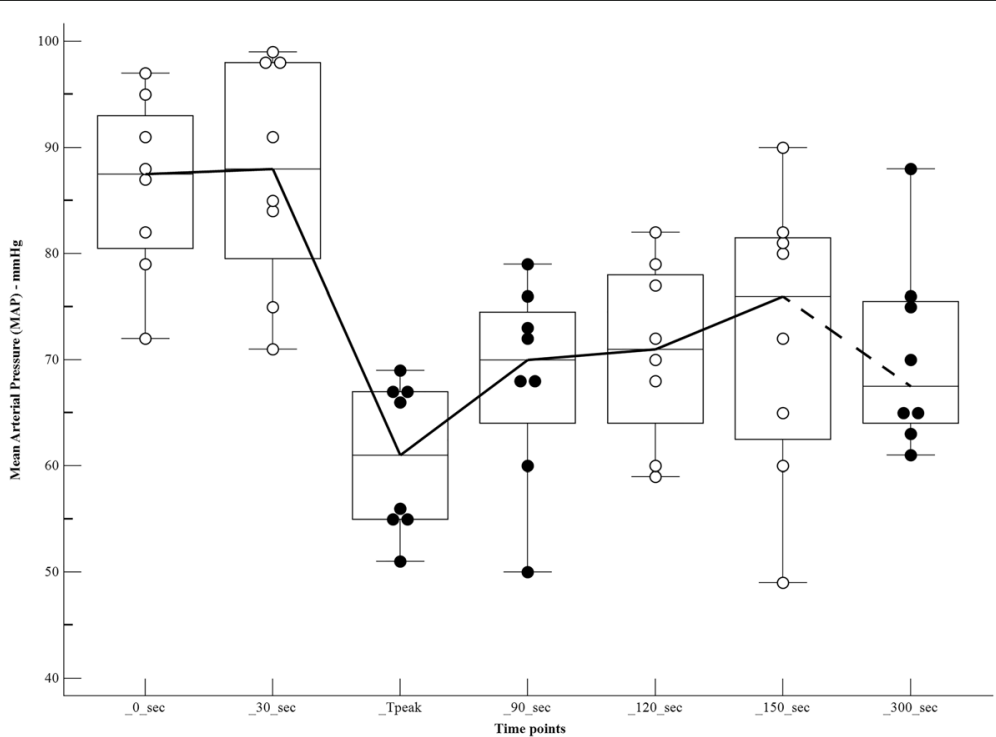

Fig. 2 Values of mean arterial pressure $(\mathrm{mmHg})$ in dogs $(n=8)$ receiving a bolus of propofol at different time points. The central box represents the values from the lower to upper quartile. The middle line represents the median. Time points non-significantly different (empty circles) and significantly different (full circles) from the baseline 


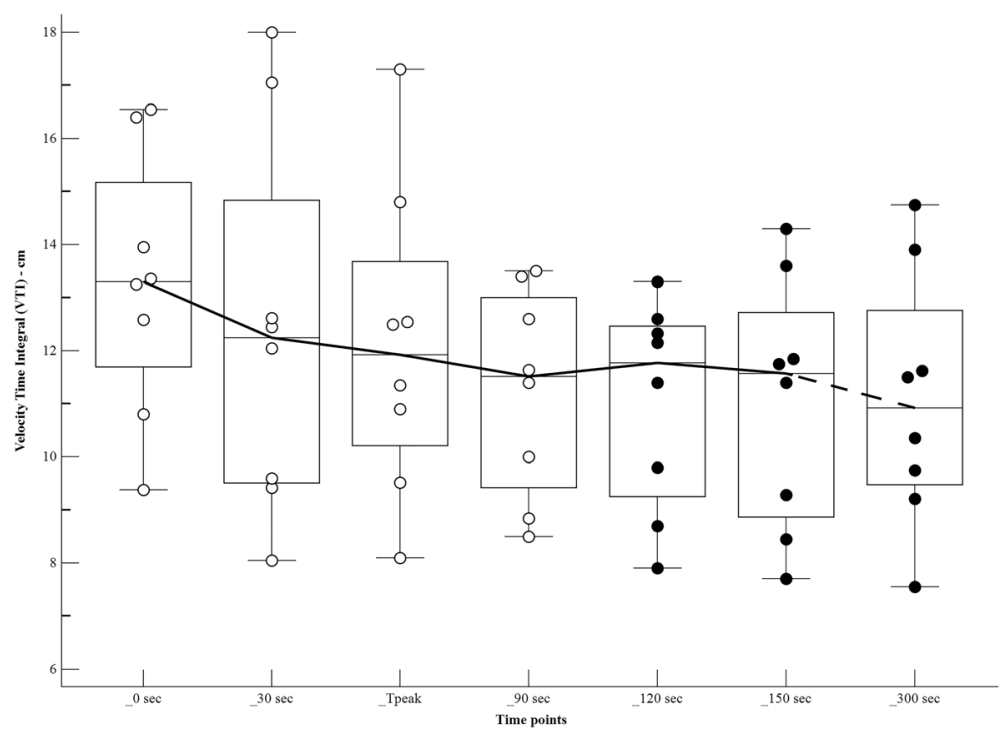

Fig. 3 Values of velocity time integral (centimetres) in dogs $(n=8)$ receiving a bolus of propofol at different time points. The central box represents the values from the lower to upper quartile. The middle line represents the median. Time points non-significantly different (empty circles) and significantly different (full circles) from the baseline

depression, it is likely that a drop in BP in this species occurs mainly by a centrally mediated mechanism. Based on findings of our study in dogs the MAP_Tpeak happens much earlier than the peak effect after a bolus of propofol. This would suggest that haemodynamic depression may not be mainly mediated by a central mechanism but could rather be a peripheral interaction within the vascular bed.

The study setting presented in this work offers an acceptable solution when studying rapidly occurring hemodynamic events in a clinical environment. These studies have to accomplish with two substantial requirements, a continuous beat-to-beat monitoring, enable recording instantaneous variations of hemodynamic variables and an ethically acceptable way of doing it. Both transthoracic echocardiography and invasive blood pressure measurement could provide the above-mentioned tasks, allowing us to collect data before and over the entire induction time. Moreover, adequate equipment and clinical competence to run this type of

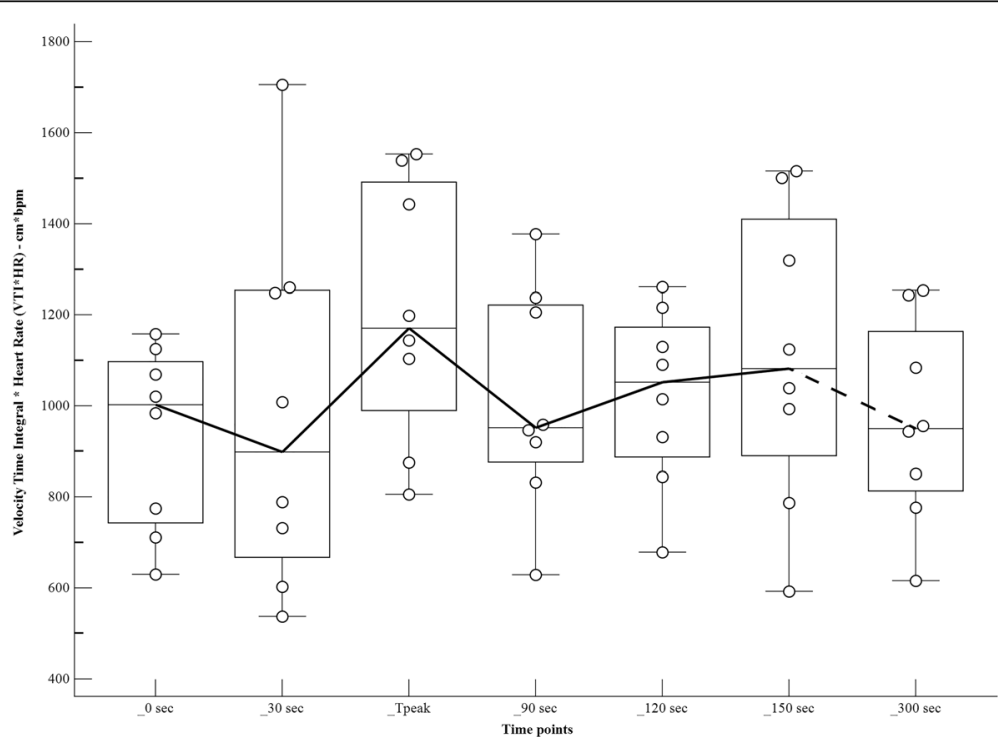

Fig. 4 Values of velocity time integral*heart rate (centimetres*beats minute $\left.{ }^{-1}\right)$ in dogs $(n=8)$ receiving a bolus of propofol at different time points. The central box represents the values from the lower to upper quartile. The middle line represents the median. Time points nonsignificantly different (empty circles) and significantly different (full circles) from the baseline 
cardiac scanning and images interpretation are commonly available in the vast majority of the veterinary hospitals.

A significant increase in heart rate after propofol administration was previously reported, but in chronically instrumented dogs [1, 2]. Other authors found a non-statistically-significant increase in heart rate after BP drop following induction with similar dose of propofol $[4,5,7]$, however, cardiovascular variables were not measured immediately after injection of propofol and continuous monitoring methods were not used.

Without actual determinations of plasma propofol concentrations the predictions of the pharmacokinetics simulation could be imprecise, as related to the predictive performance of the Beths PK model (median bias of the predictions $-3.05 \%$, median inaccuracy $27.15 \%$ in their validation study). In addition, the effect-site equilibration constant used to describe the delay equilibration between the plasma concentration and the drug effect, could not be the most accurate. The value of $\mathrm{K}_{\mathrm{e} 0}$ can be determined from complex studies combining blood concentrations with frequent measurements of drug effect, unfortunately, in the dog, it has been little studied.

Considering that the reduction in blood pressure following a bolus of propofol is closely related to blood plasma drug concentration, a different speed of injection of the bolus may well have produced different degrees of variation in blood pressure within this group of dogs, especially as this finding has already been demonstrated in sheep [34].

This study has some limitations. The use of acepromazine and methadone as a premedication before propofol induction may have had some impact on the cardiovascular system. Acepromazine is an $\alpha 1$-adrenergic receptor antagonist that induces dose-dependent negative haemodynamic changes in dogs: a low dose of $0.05 \mathrm{mg} / \mathrm{kg}$ (three times the dose used in this study) administered IV has been shown to potentiate isoflurane-induced vasodilation without altering $\mathrm{CO}$ [35]. However, the same dose administered intramuscularly was shown to reduce $\mathrm{BP}$ at 5 and $15 \mathrm{~min}$ and $\mathrm{HR}$ at $5 \mathrm{~min}$, compared with baseline values [36]. Methadone alone could cause dose-dependent sedation and a decrease in HR [37], an effect most likely attributable to a centrally mediated increase in vagal tone [38]. Nevertheless, premedication facilitated arterial catheter placement, reduced the pre-operative stress and excitement in dogs which itself would have had a greater haemodynamic influence, due to sympathetic stimulation, and allowed to use properly the Beths PK model for propofol.

In this study the minute distance, used as analogue of $\mathrm{CO}$, did not change significantly at MAP_Tpeak (mild increase). However, considering the fairly small number of subject, it is possible that a significant effect was not detected. Despite this limitation of the study, our finding is consistent with previous results in premedicated [7] or unpremedicated $[2,3]$ dogs, in which $\mathrm{CO}$ remained essentially unchanged from the pre-induction value after administration of a similar or higher dose of propofol (4 to $15 \mathrm{mg} / \mathrm{kg}$ ). Nevertheless, neither SV nor CO was directly measured throughout this study. The $\mathrm{CO}$ can be calculated by multiplying the cross-sectional area of the aorta *VTI * HR, however, comparing different values on the same subject, the first can be omitted in the calculation. In order to measure SV variation, the left ventricular outflow tract (LVOT) VTI was monitored. LVOT-VTI, or 'stroke distance', is commonly used as SV surrogate to measure variation of the left ventricular ejection on the same subject in human clinical studies [24-27]. Its use is reported also in animals [21-23]. VTI*HR, or 'minute distance', is directly related to cardiac output and has often been used as a useful alternative measure to evaluate the $\mathrm{CO}$, particularly when more invasive methods are not available [21, 27, 39-41].

In this study, neither apnoea, nor other anaesthetic-related adverse effects were observed during induction and in the following minutes, despite these reported to be possible after propofol administration in other studies [42, 43]. Observing $\mathrm{HR}$ trend at the different time points a second peak at $150 \mathrm{~s}$ can be notice. This could be a consequence of a sympathetic stimulation, due to endotracheal intubation [32].

\section{Conclusions}

In conclusion, this study has found that in healthy premedicated dogs, a bolus of propofol administered IV over $30 \mathrm{~s}$ causes a transitory drop in blood pressure, however the cardiac output was well maintained due to a raise in heart rate. We have also found that MAP_Tpeak happens closely to predicted Cmax and, therefore, their magnitude may be strictly related. To investigate how other drugs commonly used as part of canine anaesthetic protocols (such as alpha2-agonists or short-acting opioids) can affect reflex heart rate response following propofol administration, and how a reduction of the magnitude of Cmax can mitigate MAP_Tpeak, may be an interesting field of research.

\section{Abbreviations \\ BP: Blood pressure; Cmax: Estimated peak plasma concentration of propofol; CO: Cardiac output; HR: Heart rate; IV: Intravenous; LVOT: Left ventricular outflow tract; MAP: Mean invasive arterial blood pressure; MAP_Tpeak: Lowest MAP recorded; PK: Pharmacokinetic; SV: Stroke volume; Tpeak: Moment of maximum hemodynamic depression; VTI: Velocity time integral}

\section{Acknowledgements}

The authors thank Barbara Contiero for technical assistance.

\section{Funding}

This research did not receive any specific grant from funding agencies in the public, commercial, or not-for-profit sectors.

Availability of data and materials

The datasets used and/or analysed during the current study are available from the corresponding author on reasonable request. 


\section{Authors' contributions}

AC and RR designed the study, acquired and analyzed the data. HF, Ml and PF contributed to the interpretation of data, drafting and revision of the manuscript. All authors participated in writing the manuscript and approved the final version

\section{Ethics approval}

This study was done with agreement of the Ethic Committee (protocol number: 89556) of the University of Padua (O.P.B.A.).

\section{Consent for publication}

Not applicable

\section{Competing interests}

The authors declare that they have no competing interests.

\section{Publisher's Note}

Springer Nature remains neutral with regard to jurisdictional claims in published maps and institutional affiliations.

\section{Author details}

'Department of Animal Medicine, Production and Health, Agripolis, Università degli Studi di Padova, Padua, Italy. ${ }^{2}$ CVRS - Policlinico Veterinario Roma Sud, Rome, Italy. ${ }^{3}$ Specialist Veterinary Cardiology Consultancy, Lymington Bottom, Four Marks, Hampshire, UK.

Received: 9 October 2017 Accepted: 31 August 2018

Published online: 12 September 2018

\section{References}

1. Mayer N, Legat K, Weinstabl C, Zimpfer M. Effects of propofol on the function of normal, collateral-dependent, and ischemic myocardium. Anesth Analg. 1993;76:33-9.

2. Wouters PF, Van de Velde M, Marcus M, Deruyter HA, Van Aken H. Hemodynamic changes during induction of anesthesia with eltanolone and propofol in dogs. Anesth Analg. 1995;81:125-31.

3. Quandt JE, Robinson EP, Rivers WJ, Raffe MR. Cardiorespiratory and anesthetic effects of propofol and thiopental in dogs. Am J Vet Re. 1998;59: 1137-43.

4. Musk GC, Pang DS, Beths T, Flaherty DA. Target-controlled infusion of propofol in dogs--evaluation of four targets for induction of anaesthesia. Vet Rec. 2005:157:766-70.

5. Sams L, Braun C, Allman D, Hofmeister E. A comparison of the effects of propofol and etomidate on the induction of anesthesia and on cardiopulmonary parameters in dogs. Vet Anaesth Analg. 2008;35:488-94.

6. Silva A, Ribeiro LM, Bressan N, Oliveira P, Ferreira DA, Antunes LM. Dogs mean arterial pressure and heart rate responses during high propofol plasma concentrations estimated by a pharmacokinetic model. Res Vet Sci. 2011:91:278-80

7. Henao-Guerrero N, Riccó CH. Comparison of the cardiorespiratory effects of a combination of ketamine and propofol, propofol alone, or a combination of ketamine and diazepam before and after induction of anesthesia in dogs sedated with acepromazine and oxymorphone. Am J Vet Re. 2014;75:231-9.

8. Goodchild CS, Serrao JM. Cardiovascular effects of Propofol in the anesthetized dog. Br J Anaest. 1989:63:87-92.

9. Pagel PS, Hettrick DA, Kersten JR, Lowe D, Warltier DC. Cardiovascular effects of propofol in dogs with dilated cardiomyopathy. Anesthesiology. 1998;88:180-9

10. Claeys MA, Gepts E, Camu F. Haemodynamic changes during anaesthesia induced and maintained with propofol. Br J Anaesth. 1988;60:3-9.

11. Pagel PS, Warltier DC. Negative inotropic effects of propofol as evaluated by the regional preload recruitable stroke work relationship in chronically instrumented dogs. Anesthesiology. 1993;78:100-8.

12. Nagashima Y, Furukawa Y, Chiba S. Propofol decreases contractility of isolated blood-perfused left ventricular muscle in the dog. J Anesth. 2000; 14:45-7.

13. Fujinaka W, Shimizif J, Iribe G, Imaoka T, Oshima Y, Kiyooka T, Morita K, Mohri S. Efects of propofol on left ventricular mechanoenergetics in the excised cross-circulated canine heart. Acta Med Okayama. 2012;66:435-42.

14. Cullen PM, Turtle M, Prys-Roberts C, Way WL, Dye J. Effect of propofol anesthesia on baroreflex activity in humans. Anesth Analg. 1987;66:1115-20.
15. Blake DW, Jover B, Mcgrath BP. Haemodynamic and heart rate reflex responses to propofol in the rabbit: Comparison with althesin. $\mathrm{Br} J$ Anaesth 1988;61:194-9.

16. Sellgren J, Biber B, Henriksson B, Martner J, Pontén J. The effects of propofol, methohexitone and isoflurane on the baroreceptor reflex in the cat. Acta Anaesthesiol Scand. 1992;36:784-90.

17. Ebert TJ, Muzi M, Berens R, Goff D, Kampine JP. Sympathetic response to induction of anesthesia in humans with propofol or etomidate. Anesthesiology. 1992;76:725-33.

18. Sato M, Tanaka M, Umehara S, Nishikawa T. Baroreflex control of heart rate during and after propofol infusion in humans. Br J Anaesth. 2005;94:577-81.

19. Saeian K, Wann LS, Sagar KB. Doppler echocardiographic evaluation of left ventricular function. Echocardiography. 1990;7:21-5.

20. Yang HS, Song BG, Kim JY, Kim SN, Kim TY. Impact of propofol anesthesia induction on cardiac function in low-risk patients as measured by intraoperative Doppler tissue imaging. J Am Soc Echocardiogr. 2013:26:727-35.

21. Sohn S, Kim HS, Han JJ. Doppler flow velocity measurement to assess changes in Inotropy and Afterload: a study in healthy dogs. Echocardiography. 2002;19:207-13.

22. Young LE, Blissitt KJ, Clutton RE, Molony V. Haemodynamic effects of a sixty minute infusion of dopamine hydrochloride in horses anaesthetised with halothane. Equine Vet J. 1998;30:310-6.

23. Slama M, Masson H, Teboul J, Arnout M, Susic D, Frohlich E, Andrejak M. Respiratory variations of aortic VTI: a new index of hypovolemia and fluid responsiveness. Am J Physiol Heart Circ Physiol. 2002;283:1729-33.

24. Thomas DE, Yousef ZR, Fraser AG. A critical comparison of echocardiographic measurements used for optimizing cardiac resynchronization therapy: stroke distance is best. Eur J Heart Fail. 2009;11:779-88.

25. Pereira de Souza Neto E, Grousson S, Duflo DFC, Joly H, Convert J, Mottolese C, Dailler F, Cannesson M. Predicting fluid responsiveness in mechanically ventilated children under general anaesthesia using dynamic parameters and transthoracic echocardiography. Br J Anaesth. 2011;106:856-64.

26. Navaratnam M, Punn R, Ramamoorthy T, Tacy TA. LVOT-VTI is a useful Indicator of low ventricular function in young patients. Pediatr Cardiol. 2017; 38:1148-54.

27. Richardson JR, Ferguson J, Hiscox J, Rawles J. Non-invasive assessment ofcardiac output in children. J Accid Emerg Med. 1998;15:304-7.

28. Lewis JF, Kuo LC, Nelson JG, Limacher MC, Quinones MA. Pulsed Doppler echocardiographic determination of stroke volume and cardiac output: clinical validation of two new methods using the apical window. Circulation. 1984;70:425-31.

29. Beths T, Reid J, Monteiro AM, Nolan AM. Evaluation and optimisation of a target controlled infusion system for administering propofol to dogs as part of a total intravenous anaesthetic technique during dental surgery. Vet Rec. 2001;148:198-203

30. Brás S, Bressan N, Ribeiro L, Ferreira DA, Antunes L, Nunes CS. A step towards effect-site target-controlled infusion with propofol in dogs: a k(e0) for propofol. J Vet Pharmacol Ther. 2009;32:182-8.

31. Ismail EF, Kim SJ, Salem R, Crystal GJ. Direct effects of Propofol on myocardial contractility in in situ canine hearts. Anesthesiology. 1992;77:964-72.

32. Billard V, Moulla F, Bourgain JL, Megnigbeto A, Stanski DR. Hemodynamic response to induction and intubation. Anesthesiology. 1994:81:1384-93.

33. Struys MM, Coppens MJ, De Neve N, Mortier EP, Doufas AG, Van Bocxlaer JF, Shafer SL. Influence of administration rate on propofol plasma-effect site equilibration. Anesthesiology. 2007;107:386-96.

34. Zheng D, Upton RN, Martinez AM, Grant C, Ludbrook GL. The influence of the bolus injection rate of Propofol on its cardiovascular effects and peak blood concentrations in sheep. Anesth Analg. 1998:86:1109-15.

35. Sinclair MD, Dyson DH. The impact of acepromazine on the efficacy of crystalloid, dextran or ephedrine treatment in hypotensive dogs under isoflurane anesthesia. Vet Anaesth Analg. 2012:39:563-73.

36. Grasso SC, Ko JC, Weil AB, Paranjape V, Constable PD. Hemodynamic influence of acepromazine or dexmedetomidine premedication in isoflurane-anesthetized dogs. J Am Vet Med Assoc. 2015;246:754-64.

37. Menegheti TM, Wagatsuma JT, Pacheco AD, Perez B, Pacheco CM, Abimussi CJ, dos Santos PP, de Souza Oliva VN. Electrocardiographic evaluation of the degree of sedation and the isolated use of methadone in healthy dogs. Vet Anaesth Analg. 2014;41:97-104.

38. Stanley TH, Liu WS, Webster LR, Johansen RK. Haemodynamic effects of intravenous methadone anaesthesia in dogs. Can Anaesth Soc J. 1980;27:52-7. 
39. Weiner Z, Farmakides G, Schulman H, Casale A, Itskovitz-Eldor J. Central and peripheral haemodynamic changes in post-term fetuses: correlation with oligohydramnios and abnormal fetal heart rate pattern. Br J Obstet Gynaecol. 1996:103:541-6.

40. Grow MP, Singh A, Fleming NW, Young N, Watnik M. Cardiac output monitoring during off-pump coronary artery bypass grafting. J Cardiothorac Vasc Anesth. 2004;18:43-6.

41. Goldberg DJ, French B, Szwast AL, McBride MG, Marino BS, Mirarchi N, Hanna BD, Wernovsky G, Paridon SM, Rychik J. Impact of sildenafil on echocardiographic indices of myocardial performance after the fontan operation. Pediatr Cardiol. 2012;33:689-96.

42. Smith JA, Gaynor JS, Bednarski RM, Muir WW. Adverse effects of administration of propofol with various preanesthetic regimens in dogs. J Am Vet Med Assoc. 1993;202:1111-5.

43. Cattai A, Rabozzi R, Natale V, Franci P. The incidence of spontaneous movements (myoclonus) in dogs undergoing total intravenous anaesthesia with propofol. Vet Anaesth Analg. 2015:42:93-8.

Ready to submit your research? Choose BMC and benefit from:

- fast, convenient online submission

- thorough peer review by experienced researchers in your field

- rapid publication on acceptance

- support for research data, including large and complex data types

- gold Open Access which fosters wider collaboration and increased citations

- maximum visibility for your research: over $100 \mathrm{M}$ website views per year

At $\mathrm{BMC}$, research is always in progress.

Learn more biomedcentral.com/submissions 